\title{
Preliminary environmental and economic assessment of polyurethane foam produced by microwave-assisted liquefaction of riparian shrubs
}

\author{
Alessandro Cardarelli ${ }^{1}$, Franco Cotana $^{2}$, Ilaria Baffo $^{1}$, Gianluca Cavalaglio ${ }^{3}$ and Marco \\ Barbanera ${ }^{1, *}$ \\ ${ }^{1}$ Department of Economics Engineering Society and Business Organization (DEIM), University of \\ Tuscia, Largo dell'Università s.n.c., Loc. Riello, 01100 Viterbo, Italy \\ ${ }^{2}$ Biomass Research Centre, CIRIAF, University of Perugia, Via G. Duranti 67, 06125 Perugia, Italy \\ ${ }^{3}$ Pegaso Telematic University, 80143, Naples, Italy
}

\begin{abstract}
The study aims to develop a full-scale plant to produce biobased PU foam from microwave liquefaction of riparian shrubs and to evaluate its environmental burden using a cradle-to-gate, scaled-up LCA approach. Life Cycle Inventory was built on experimental data for polyol synthesis by using Response Surface Methodology (RSM) to maximize the liquefaction yield. Bio-based PU foam was also compared with the petrochemical counterpart. Life Cycle Assessment was carried out using SimaPro 9.0 software and impacts were evaluated with EPD 2007 method. The results indicate that the methylene diphenyl diisocyanate production and the energy consumption for the liquefaction step are the major sources of impacts. Overall, the environmental superiority of biobased polyurethane cannot always be claimed with respect to their fossil counterpart. Finally, a simplified economic assessment showed that for the bio-based PU foam an interesting profitability could be obtained for a market price of $4.5 € / \mathrm{kg}$.
\end{abstract}

\section{Introduction}

Polyurethane (PU) foams have several applications in industry, such as in construction, packaging, and furniture production [1]. However, the raw materials used for the production of PU, polyol and isocyanate, are usually obtained from petroleum [2]. The rising attention towards the environmental sustainability and the rapid depletion of fossil fuels has led to a lot of efforts being focused on substituting petroleum-based polyols with bio-based ones, such as bio-polyol derived from the liquefaction of biomass [3].

The liquefaction process is an interesting option to convert lignocellulosic biomass into useful bio-polyol. It allows to break down the chemical components of biomass (cellulose,

\footnotetext{
* Corresponding author: $\underline{\text { m.barbanera@unitus.it }}$
} 
hemicellulose, and lignin) into hydroxyl-rich products, including solid residue and liquid bio-polyol, which consists of carbohydrate derivatives, esters, ethers, glycols and acids. Currently, several kinds of biomass have been liquefied to prepare bio-based PU, such as lignin [4], cornstalk [5], wheat straw [6]. In this paper, for the first time, riparian woody shrubs have been considered as raw material. The riparian vegetation is characterized by different ecosystems based on the characteristics of the watercourse where they grow. The management of the riverbanks is an important, although expensive, activity for the conservation and safeguarding of the territory because the vegetation affects ecological and hydraulic aspects of the river ecosystem. Therefore, riverbanks should be subjected to regular maintenance, which can produce a considerable amount of residual shrub and wood biomass.

Till now researches has been primarily focused on the optimization of the liquefaction process, improving the yield and quality of the bio-polyol, which is a fundamental prerequisite for cost-effective PU foam production. However, a detailed life cycle assessment (LCA) of the entire process should be carried out to understand the environmental feasibility of the process and to make bio-based PU foam from microwave liquefaction of biomass more competitive. LCA is a useful tool that provides a comprehensive understanding of the environmental impacts associated with a product or a service [7]. However, a limited number of studies considering the environmental performance of partially bio-based PU foam do exist so far. Manzardo et al. [8] compared the environmental performance of six partially biobased formulations (by using biobased polyols obtained from azelaic acid and/or lignin) and one fossil-based. The results showed that formulations containing azelaic-acid derived polyol and lignin-based polyol had better than fossil counterpart for all the impact categories considered. Marson et al. [9] presented an LCA study on the use of recycled polyol from glycolysis for the production of PU foam, demonstrating that it allows to decrease the environmental impacts of PU foams if compared to the use of virgin polyol.

However, no studies related to the LCA of biobased PU foams produced from polyols obtained by the biomass liquefaction have been published yet. Thus, the aim of this study is to analyze the environmental impact of the production of bio-based PU foam at an industrial scale by employing polyols obtained from the microwave liquefaction of riparian shrub biomass. In order to carry out a more significant comparison with PU foam from petroleum-based polyol, the process has been modelled at full-scale based on laboratoryscale data. Finally, a simplified economic assessment was performed for the production of bio-based PU foam considering credits for $\mathrm{CO}_{2}$ consumption.

\section{Materials and methods}

The study was carried out according to the ISO 14040 and ISO 14044 guidelines [10, 11]. LCA software SimaPro 9.0 by Pré Consultants was employed to create the LCA model and the Ecoinvent database was used as a source of life cycle background data.

\subsection{Goal and scope definition}

The study aimed to carry out a cradle-to-gate LCA of PU foam using polyol from microwave liquefaction of riparian shrub biomass. The functional unit used to perform the analysis was $1 \mathrm{~kg}$ of PU foam. The system boundaries for the life cycle assessment of the bio-based PU foam are shown in Fig. 1 where the production process is divided into three subsystems: biomass pretreatment (S1), polyol production (S2), and PU foam production (S3). Riparian shrub biomass was considered burden-free, assigning zero burdens from activities prior to its collection. Transport activities were excluded from the system 
boundaries because it was assumed that all processing stages are carried out in the same plant.

Furthermore, bio-based PU foam was compared with the petrochemical PU foam (obtained from petrochemical polyether polyol) available in the Ecoinvent database.

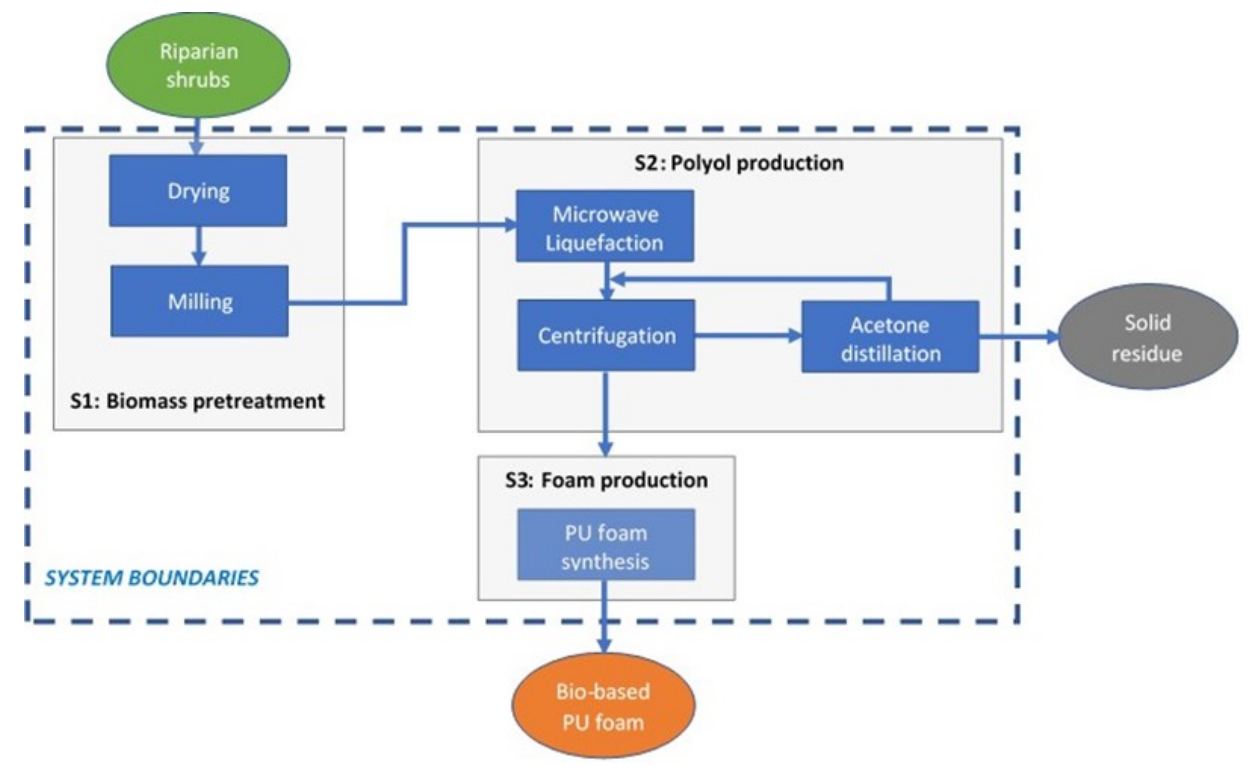

Fig. 1. System boundaries of bio-based PU foam production.

\subsection{Life cycle inventory analysis}

Life cycle inventory is the most labor-intensive and time-consuming step in LCA, due to the data required that should be consistent in order to obtain accurate environmental results. In the bio-based PU foam production process, several mass and energy flows should be determined and those referred to as the polyol production were modelled at full scale, starting from data obtained at laboratory scale. The scale-up sequence proposed by Piccinno et al. [12], [13] was applied by assuming a plant size of 10,000 ton/yr of riparian shrubs (moisture content: 50\%). Furthermore, the environmental impacts due to the capital goods and the end of the useful life of infrastructure and equipment were excluded from the study because they were considered negligible. This assumption is in line with what reported by Koch et al. [14], according to whom the impacts of the construction of a biochemical plant are not significant in terms of a long-lasting lifetime with many production hours.

A detailed description of the mass and energy flows associated with each section are reported in Table 1 and described in the following sections.

\subsubsection{Biomass pretreatment (S1)}

Firstly, feedstock should be dried up to $10 \%$ moisture content in a rotary-drum dryer. The heat required for biomass drying was calculated as the sum of four contributions such as: 
Table 1. Life Cycle Inventory data for the production of bio-based FU foam. Data are reported per kg of product obtained.

\begin{tabular}{|c|c|}
\hline \multicolumn{2}{|c|}{ Inputs from technosphere } \\
\hline \multicolumn{2}{|c|}{ Biomass pretreatment (S1) } \\
\hline Electricity & $5.29 \mathrm{kWh}$ \\
\hline Heat & $0.05 \mathrm{kWh}$ \\
\hline Polyol production (S2) \\
\hline Electricity & $1.82 \mathrm{kWh}$ \\
\hline Heat & $0.09 \mathrm{kWh}$ \\
\hline Ethanol & $1.65 \mathrm{~kg}$ \\
\hline Glycerol & $1.65 \mathrm{~kg}$ \\
\hline Sulphuric acid & $67,2 \mathrm{~g}$ \\
\hline Acetone & $27 \mathrm{~g}$ \\
\hline Foam production (S3) \\
\hline Electricity & $0.417 \mathrm{kWh}$ \\
\hline DMI & $0.616 \mathrm{~kg}$ \\
\hline Pentane & $0.054 \mathrm{~kg}$ \\
\hline Outputs to technosphere \\
\hline Emissions into air \\
\hline Acetone & $7.7 \mathrm{~g}$ \\
\hline Pentane & $3 \mathrm{~g}$ \\
\hline Waste to treatment \\
\hline Solid residue & $38.4 \mathrm{~g}$ \\
\hline
\end{tabular}

sensitive heat $\left(\mathrm{Q}_{1}\right)$ necessary to heat the water from the initial temperature of the feedstock to the wet bulb temperature at which evaporation occurs $\left(100^{\circ} \mathrm{C}\right)$ :

$$
\mathrm{Q}_{1}=\mathrm{E} * \mathrm{C}_{\mathrm{w}} *\left(\mathrm{~T}_{\mathrm{be}}-\mathrm{T}_{\mathrm{se}}\right)
$$

where $\mathrm{E}$ is the water content to be evaporated $\left(64 \mathrm{~g} / \mathrm{kg}\right.$ PU foam), $\mathrm{C}_{\mathrm{W}}$ the specific heat of the water $\left(1 \mathrm{kcal} / \mathrm{kg}^{\circ} \mathrm{C}\right), \mathrm{T}_{\text {be }}$ is the wet bulb temperature of the incoming air $100{ }^{\circ} \mathrm{C}$, $\mathrm{T}_{\mathrm{se}}$ is the inlet wet biomass temperature $\left(10^{\circ} \mathrm{C}\right)$;

$>$ latent heat $\left(\mathrm{Q}_{2}\right)$ necessary to vaporize the water at the wet bulb temperature, equal to:

$$
\mathrm{Q}_{2}=\mathrm{E} * \lambda_{\mathrm{ev}}
$$

where $\lambda_{\mathrm{ev}}$ is the latent heat of evaporation of the water at the wet bulb temperature $\left(100{ }^{\circ} \mathrm{C}\right)$, that is equal to $2257 \mathrm{~kJ} / \mathrm{kg}$;

$>$ sensitive heat $\left(\mathrm{Q}_{3}\right)$ necessary to bring the produced steam from the wet bulb temperature to the air outlet temperature from the dryer $\left(\mathrm{T}_{\mathrm{au}}\right)$ :

$$
\mathrm{Q}_{3}=\mathrm{E} * \mathrm{C}_{\mathrm{vap}} *\left(\mathrm{~T}_{\mathrm{au}}-\mathrm{T}_{\mathrm{be}}\right)
$$

where $\mathrm{C}_{\text {vap }}$ is the average specific heat of water vapor between the two temperatures $\mathrm{T}_{\mathrm{au}}\left(110{ }^{\circ} \mathrm{C}\right)$ and $\mathrm{T}_{\mathrm{be}}$, that is equal to $0.466 \mathrm{kcal} / \mathrm{kg}^{\circ} \mathrm{C}$;

$>$ sensitive heat $\left(\mathrm{Q}_{4}\right)$ necessary to heat the dried biomass from the inlet temperature $\left(\mathrm{T}_{\mathrm{se}}=\right.$ $\left.10^{\circ} \mathrm{C}\right)$ to the outlet temperature $\left(\mathrm{T}_{\mathrm{su}}=100^{\circ} \mathrm{C}\right)$ :

$$
\mathrm{Q}_{4}=\mathrm{W} * \mathrm{C}_{\mathrm{s}} *\left(\mathrm{~T}_{\mathrm{su}}-\mathrm{T}_{\mathrm{se}}\right)
$$

where $C_{s}$ is the specific heat of the dry solid $\left(2910 \mathrm{~J} / \mathrm{kg}^{\circ} \mathrm{C}\right)$. 
An electric hammer mill is then used to crush dried biomass into smaller and uniform particles, and then sorted and screened to achieve the selected size $(1 \mathrm{~mm})$. The electricity consumption associated to the milling step was determined on the basis of the modified Rittinger equation, reported by Naimi and Sokhansanj [15], assuming k'R equal to $278 \mathrm{~J}$ $\mathrm{mm} / \mathrm{g}$ and $\mathrm{Lp}$ of $1 \mathrm{~mm}$.

\subsubsection{Polyol production (S2)}

Mass and energy flows of the liquefaction step were obtained from lab-scale tests. The feedstock was harvested from the Umbrian section of Montecalvello ditch (Italy), a river section affected by cleaning operations of the riverbed and banks. In particular, the shrub layer is represented mostly by Cornus mas L., Prunus spinosa L., Ligustrum vulgare L., Corylus avellana L., Crataegus monogyna Jacq., Sambucus nigra L. Shrub vegetation, covering a riparian area of $1 \mathrm{~m}^{2 *} 1 \mathrm{~m}^{2}$, was sampled and, then, milled and dried. The chemical composition of the riparian shrubs was as follows: cellulose $(32.04 \%)$, hemicellulose (17.32\%), lignin (22.19\%), hot-water extractives (4.29\%). The characterization of feedstock was established as reported by Cotana et al. [16].

Liquefaction of biomass was carried out by using the equipment described by Barbanera et al. [17]. $4 \mathrm{~g}$ of riparian shrubs (moisture content of 10\%) were placed into the vessel with a magnetic stirring bar; a mixture of ethanol and glycerol (at the fixed ratio of 1:1) as a solvent and $2 \%$ sulfuric acid, based on the weight of the solvent, have been added.

In order to define the optimal process temperature, reaction time and solvent-to-biomass (S:L) ratio in terms of the liquefaction yield the Response Surface Methodology coupled with Box-Behnken Design (BBD), with a total of 15 experimental runs and 3 replications of central point, was employed (Tab. 2). The experiment was performed at three different temperature ranges $\left(170-190^{\circ} \mathrm{C}\right)$ with different $\mathrm{S}: \mathrm{L}$ ratio $(0.125$ to 0.25$)$ and reaction time (30-90 min).

The liquefaction yield was calculated according to Eq. (5):

$$
\mathrm{Y}(\%)=\left(\mathrm{M}_{\mathrm{O}} / \mathrm{M}_{\mathrm{S}}\right) * 100
$$

where $\mathrm{M}_{\mathrm{S}}$ is the initial mass of biomass and $\mathrm{M}_{\mathrm{O}}$ is the mass of the solid residue.

Optimization of the process variables settings was performed using the Response Optimizer tool in Minitab 18 statistical software and maximum liquefaction yield of $93.7 \%$ was obtained at these operating conditions: $185^{\circ} \mathrm{C}, 30 \mathrm{~min}, 0.125$.

The statistical analysis of the model was evaluated using analysis of variance which showed that the model is statistically significant with an F-value of 17.28. Furthermore, the model has a high correlation coefficient $\left(\mathrm{R}^{2}=0.9689\right)$ between the predicted and experimental liquefaction yield (\%), revealing that about $96.89 \%$ variations of the response could be explained by the model.

In order to verify if the obtained bio-based polyol was comparable to the commercially available petrochemical polyols, its main properties were analysed. In particular, the acid number and the hydroxyl number were determined according to ASTM D4662-08 and ASTM D4274-05D, respectively. Obtained polyol has a hydroxyl value of $612.02 \mathrm{mg}$ $\mathrm{KOH} / \mathrm{g}$ and an acid number of $17.08 \mathrm{mg} \mathrm{KOH} / \mathrm{g}$, demonstrating that polyol is suitable for the synthesis of polyurethane [18].

The electricity use for the microwave liquefaction at lab-scale was evaluated from the power vs time curve that is integrated by the software of the microwave device, obtaining a value of $27.5 \mathrm{Wh} / \mathrm{g}$ of dried biomass at the optimal operating condition. In order to calculate the electricity consumption at industrial scale, a reduction in the specific energy 
consumption of $90 \%$ was assumed, according to the results obtained by Bermudez et al. [19].

Table 2. Box-Behnken Design and liquefaction yield distribution.

\begin{tabular}{|c|c|c|c|}
\hline Temperature $\left({ }^{\circ} \mathbf{C}\right)$ & Time (min) & S:L & Y (\%) \\
\hline $\mathbf{1 8 0}$ & 60 & 0.1875 & 76.41 \\
\hline $\mathbf{1 7 0}$ & 90 & 0.1875 & 62.05 \\
\hline $\mathbf{1 9 0}$ & 90 & 0.1875 & 77.78 \\
\hline $\mathbf{1 9 0}$ & 60 & 0.25 & 72.32 \\
\hline $\mathbf{1 8 0}$ & 30 & 0.25 & 71.59 \\
\hline $\mathbf{1 8 0}$ & 90 & 0.125 & 83.89 \\
\hline $\mathbf{1 8 0}$ & 60 & 0.1875 & 76.17 \\
\hline $\mathbf{1 7 0}$ & 60 & 0.25 & 59.99 \\
\hline $\mathbf{1 8 0}$ & 90 & 0.25 & 86.38 \\
\hline $\mathbf{1 9 0}$ & 60 & 0.125 & 82.07 \\
\hline $\mathbf{1 7 0}$ & 30 & 0.1875 & 65.31 \\
\hline $\mathbf{1 9 0}$ & 30 & 0.1875 & 81.34 \\
\hline $\mathbf{1 7 0}$ & 60 & 0.125 & 66.91 \\
\hline $\mathbf{1 8 0}$ & 30 & 0.125 & 89.62 \\
\hline & 60 & 0.1875 & 76.87 \\
\hline
\end{tabular}

After liquefaction, vessels are cooled to room temperature and the liquefaction products are dissolved in acetone and then filtered under vacuum in order to separate the solid residue from the filtrate. The amount of acetone was assumed to be equal to that actually used on a laboratory scale, while the consumption of electricity of the filtration unit was assumed to be $5.5 \mathrm{kWh} /$ ton of filtered material, as indicated by Piccinno et al. [12].

The filtered liquid, containing polyol and acetone, is sent to a distillation unit in order to recover the solvent, while the solid residue is assumed to be disposed of in landfill.

Heat demand $\left(\mathrm{Q}_{\text {dist }}\right)$ of the distillation unit was calculated according to Eqs. 6-8, as the sum of the thermal energy required to heat the mixture to the boiling point of acetone and that needed to vaporize the distillate [20].

$$
\left.\alpha=10^{\left(8.9^{T_{a}-T_{\text {boil }}} T_{\text {a }}+T_{\text {bil }}\right.}\right)
$$

where

$\alpha$ : relative volatility of the solvents;

$\mathrm{T}_{\mathrm{a}}$ : boiling temperature of polyol $(454 \mathrm{~K})$;

$\mathrm{T}_{\mathrm{b}}$ : boiling temperature of acetone $(300 \mathrm{~K})$;

$$
R_{\text {minu }}=\frac{1}{a-1}\left(\frac{X_{L D}}{X_{L F}}-\frac{\alpha\left(1-X_{L D}\right.}{1-X_{L F}}\right)
$$

where:

$\mathrm{R}_{\min }$ : minimum reflux ratio;

$\mathrm{X}_{\mathrm{LD}}$ : target purity of distillate (1);

$\mathrm{X}_{\mathrm{LF}}$ : molar fraction of acetone in feed (0.944);

$$
Q_{\text {dist }}=\frac{C_{p} * m_{\operatorname{mix}} *\left(T_{\text {loil }}-T_{0}\right)+\Delta H_{\text {Lapp }} * m_{\text {dist }} *\left(1.2 * R_{\min }+1\right)}{\text { Thent }_{\text {hant }}-0.1}
$$

where: 
$\mathrm{m}_{\text {mix }}$ : mass of the reaction mixture $(\mathrm{kg})$;

$\Delta \mathrm{H}_{\text {vap }}$ : enthalpy of vaporization (acetone: $511 \mathrm{~kJ} / \mathrm{kg}$ );

$\mathrm{m}_{\text {dist: }}$ : mass of the liquid to be vaporized $(\mathrm{kg})$;

$\eta_{\text {heat }}$ : efficiency of heating device $(90 \%)$.

According to Parvatker et al. [21], it is assumed that 5\% in mass of acetone is not recovered and that $2 \%$ is released into the atmosphere.

\subsubsection{Foam production (S3)}

The inventory for the PU foam production was taken from the Ecoinvent database, representing a European industry production average with data provided by the European plastics industry.

PU is produced by metering and mixing different streams of liquid components, containing polyols, methylene diphenyl diisocyanate (DMI), and pentane as blowing agent to generate the foam. In this study, the amount of petrochemical polyol was substituted with the same amount of bio-based polyol, by assuming that the physical performances of PU foam do not change.

In addition to the primary data, the inventory comprised secondary data for background systems, related to the production of utilities (heat, electricity) and chemicals. The main source of secondary data was the Ecoinvent database (Tab. 3).

Table 3. List of the main Ecoinvent database processes assumed for the background system.

\begin{tabular}{|c|c|}
\hline Input & Process \\
\hline Electricity & Electricity, medium voltage, at grid/IT \\
\hline Heat & Heat, natural gas, at industrial furnace $>100 \mathrm{~kW} / \mathrm{RER}$ \\
\hline Acetone & Acetone, liquid, at plant/RER \\
\hline Ethanol & Ethanol, $95 \%$ in $\mathrm{H}_{2} \mathrm{O}$, from sugar beet molasses, at distillery/CH \\
\hline Glycerol & Glycerine, from vegetable oil, at esterification plant/FR \\
\hline Sulphuric acid & Sulphuric acid, liquid, at plant/RER \\
\hline $\begin{array}{c}\text { Landfill disposal of } \\
\text { solid residue }\end{array}$ & Disposal, wood ash mixture, pure, $0 \%$ water, to landfarming \\
\hline
\end{tabular}

\subsection{Impact assessment}

To assess the potential environmental impact of the bio-based PU foam in this LCA study, the EPD 2007 Impact Assessment Method was chosen. This method was selected because it is valid for the European context. It provides information on the effects of six impact categories (global warming, ozone layer depletion, photochemical oxidation, acidification, eutrophication, non-renewable, fossil) on the environment, their contribution to the environmental performance of the overall process and which inventory data contribute to each impact.

\section{Results and discussion}

\subsection{Environmental analysis}

The results of the impact assessment are shown in Table 4, from which it can be noted that in all impact categories, the sources of greatest burden are the phases of polyol production and PU foam synthesis. 
Table 4. Environmental impacts for the production of bio-based PU foam.

\begin{tabular}{cccccc}
\hline Impact Category & Unit & $\begin{array}{c}\text { Biomass } \\
\text { pretreatment }\end{array}$ & $\begin{array}{c}\text { Polyol } \\
\text { production }\end{array}$ & $\begin{array}{c}\text { Foam } \\
\text { production }\end{array}$ & Total \\
\hline Global warming & $\mathrm{kg} \mathrm{CO}_{2}$ eq & 1.38 & 0.95 & 2.74 & 5.07 \\
Ozone layer depletion & $\mathrm{mg} \mathrm{CFC-11} \mathrm{eq}$ & 0.17 & 0.29 & 0.02 & 0.48 \\
Photochemical & $\mathrm{g} \mathrm{C}_{2} \mathrm{H}_{4}$ & 0.25 & 1.77 & 2.74 & 4.76 \\
oxidation & $\mathrm{g} \mathrm{SO}_{2}$ eq & 1.23 & 14.77 & 11.90 & 27.90 \\
Acidification & $\mathrm{kg} \mathrm{PO}^{4-}$ eq & 0.13 & 4.43 & 1.03 & 5.59 \\
Eutrophication & $\mathrm{MJ} \mathrm{eq}_{\text {Non renewable, fossil }}$ & 24.67 & 54.38 & 60.22 & 139.26 \\
\hline
\end{tabular}

One of the key issues of the study is the determination of the environmental hotspots, i.e. the operations involved in the bio-based PU foam production process that are responsible for the highest environmental burdens and energy requirements. Results of the contribution analysis (Fig. 2) allowed the identification of the life cycle phases that mostly influenced the impact assessment results.

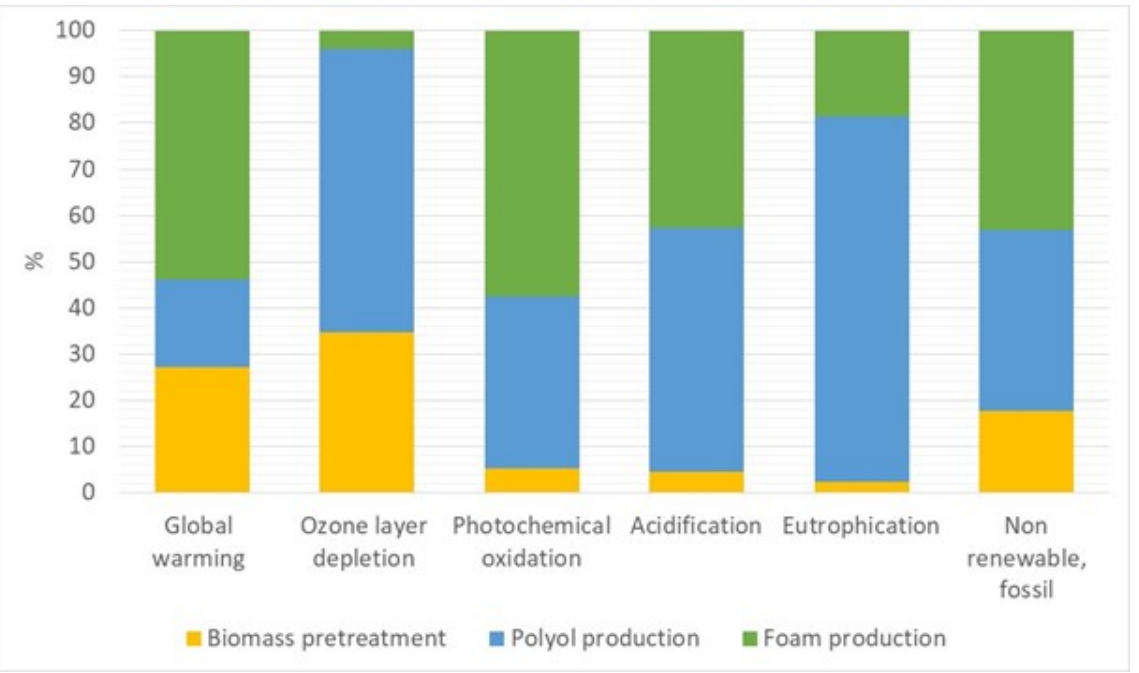

Fig. 2. Relative impact category contributions of different production phases.

Global warming impact category resulted to be strongly influenced by the PU foam synthesis mainly due to the consumption of non-renewable resources related to the application of DMI in the bio-based PU formulation. Other significant contributions are related to the drying and liquefaction processes, which account for $26.5 \%$ and $16.5 \%$ respectively, due to the energy consumption and the use of ethanol.

Ozone layer depletion category resulted to be more influenced by the impacts deriving from the liquefaction step. In this case, the reason of such results was directly associated to the consumption of electricity, ethanol and glycerol in almost equal parts.

For the photochemical oxidation category, the highest impact of the synthesis phase $(57.5 \%)$ is always due to the consumption of DMI, while, in the polyol production section, the electricity consumption during the liquefaction process and the fugitive emissions of acetone (about 15\%) in the distillation phase are the major contributors.

The acidification category resulted to be more influenced by the impacts deriving from polyol production life cycle stage, mostly due to the energy and ethanol consumption during the liquefaction step. Also, in this case, the use of DMI was another significant contribution to this impact category. 
For the eutrophication category, the main contribution is related to the ethanol production process, as it is assumed that it is obtained from sugar beet molasses, for the cultivation of which there are emissions of nitrates into the water resulting from the fertilization of the land with manure.

Finally, the non-renewable fossil category resulted to be more influenced by the impacts deriving from the PU foam production process, due to the energy consumption for the production of DMI, while the highest contributions in the polyol production step were due to the electricity consumption and the production of glycerol.

Furthermore, the environmental burdens of bio-based PU foam production from riparian shrubs were compared with those caused by PU foam from petroleum-based polyol (Tab. 5). The comparison aimed to evaluate the difference in terms of environmental burden with an already industrialized production route. The environmental footprint scores were calculated by employing the same life cycle impact assessment methodology, such as the EPD 2007. Since it was assumed that the PU foam synthesis was the same process in both scenarios, the comparison was limited to the production of polyol.

From the results, it can be seen that bio-based polyol has better performance than fossil one for the impact categories Global warming, Photochemical oxidation and Nonrenewable fossil while it is worse for the other impact categories. However, the differences between the two types of foams are less than $15 \%$ for four impact categories (Photochemical oxidation, Acidification, Eutrophication, Non-renewable fossil) while they are marked for the categories global warming and ozone layer depletion. In particular, the increase of impacts in ozone depletion confirms the results obtained by Chen et al. [22] for bio-PET, while it is in contrast with the findings found by Manzardo et al. [23] for bio-PU foam.

Table 5. Comparison of the environmental impact of bio-based and petrochemical polyol (Data are referred to $1 \mathrm{~kg}$ of polyol).

\begin{tabular}{llcc}
\hline \multicolumn{1}{c}{ Impact Category } & \multicolumn{1}{c}{ Unit } & Bio-based polyol & Fossil polyol \\
\hline Global warming & $\mathrm{kg} \mathrm{CO}_{2} \mathrm{eq}$ & 2.3 & 3.6 \\
Ozone layer depletion & $\mathrm{mg} \mathrm{CFC}-11 \mathrm{eq}$ & 0.46 & 0.001 \\
Photochemical oxidation & $\mathrm{g} \mathrm{C}_{2} \mathrm{H}_{4}$ & 2.0 & 2.3 \\
Acidification & $\mathrm{g} \mathrm{SO}_{2}$ eq & 16.2 & 14.1 \\
Eutrophication & $\mathrm{kg} \mathrm{PO}^{4-} \mathrm{eq}$ & 4.6 & 4.3 \\
Non-renewable, fossil & $\mathrm{MJ} \mathrm{eq}$ & 79.0 & 80.3 \\
\hline
\end{tabular}

As regards the global warming category, which represents one of the most significant impact categories in terms of contribution to the alteration of the environment and climate change, it should be noted that the use of bio-based polyol can guarantee a significant reduction of the burden. equal to about $35 \%$.

This result is consistent with those reported by Fridrihsone et al. [24] for the production of bio-polyol from rapeseed oil. In our study, the GHG emission savings due to the replacement of petrochemical feedstock are equal to $1.3 \mathrm{kgCO}_{2} \mathrm{eq} / \mathrm{kg}$ while Fridrihsone et al. obtained a value of $1.5-3.02 \mathrm{kgCO}_{2} \mathrm{eq} / \mathrm{kg}$. These values are interesting because Patel et al. [25] recommended that a good practice target for bio-based polymers is to avoid at least $1 \mathrm{~kg} \mathrm{CO} 2$ per $\mathrm{kg}$ polymer.

\subsection{Economic analysis}

In order to evaluate the profit of the bio-based PU foam production, a simplified valueadded economic analysis was carried out. The fixed costs of production and return on investment were excluded from this analysis, as these costs would decrease the profit predicted by the value-added economic model. In this way, it can be assumed that a 
process, not profitable based on the value-added economics, cannot be profitable with the other costs comprised.

Eq. 9 was used for the economic analysis of the value:

Gross profit $=$ Revenues - Raw materials costs - Energy costs - Disposal costs

where the revenues include the profit from sales of PU foam.

Data related to product price, raw material costs, energy (electricity and thermal energy) and disposal costs are reported in Tab. 6. Costs for landfill disposal of the solid residue produced by the liquefaction process and the revenues deriving from carbon credits generated by the replacement of fossil PU foam with bio-foam were also included. The economic analysis was performed considering the mass balance data built for the LCA analysis.

Table 6. Economic data for bio-based PU foam production.

\begin{tabular}{|l|c|c|c|}
\hline & Cost/selling price & Unit & Reference \\
\hline \multicolumn{4}{|c|}{ Raw materials } \\
\hline Riparian shrubs & 0.03 & $€ / \mathrm{kg}$ & Personal communication \\
\hline Ethanol & 0.8 & $€ / \mathrm{kg}$ & {$[6]$} \\
\hline Acetone & 1.2 & $€ / \mathrm{kg}$ & {$[6]$} \\
\hline Glycerol & 0.1 & $€ / \mathrm{kg}$ & {$[7]$} \\
\hline Sulphuric acid & 0.115 & $€ / \mathrm{kg}$ & {$[8]$} \\
\hline DMI & 2.85 & $€ / \mathrm{kg}$ & {$[9]$} \\
\hline Pentane & 1.29 & $€ / \mathrm{kg}$ & {$[10]$} \\
\hline \multicolumn{4}{|c|}{ Energy } \\
\hline Electricity & 0.15 & $€ / \mathrm{kWh}$ & https://www.arera.it/it/dati/eepcfr2.htm\# \\
\hline Thermal energy & 0.02 & $€ / \mathrm{kWh}$ & {$[11]$} \\
\hline \multicolumn{4}{|c|}{ Disposal } \\
\hline Solid residue landfilling & 0.18 & $€ / \mathrm{kg}$ & Pevensonal communication \\
\hline \multicolumn{5}{|c|}{. } & $€ / \mathrm{kg}$ & Cok et al. (2014) \\
\hline Bio-based PU foam & $2-6.5$ & $€ / \mathrm{kg}$ & https://www.qualenergia.it/ \\
\hline $\mathrm{CO}_{2}$ Credits & 0.025 & \multicolumn{4}{c|}{}
\end{tabular}

Fig. 3 shows the trend in gross profit deriving from the production of $1 \mathrm{~kg}$ of bio-foam, as its selling price varies. Interesting profitability is obtained for a selling price of $4.5 € / \mathrm{kg}$, which is higher than the current market price of polyurethane foams, which is around 2-3 $€ / \mathrm{kg}$ [26]. In particular, it should be noted that production costs are mainly related to the use of ethanol (34.3\% of total production costs) and DMI (45.7\%).

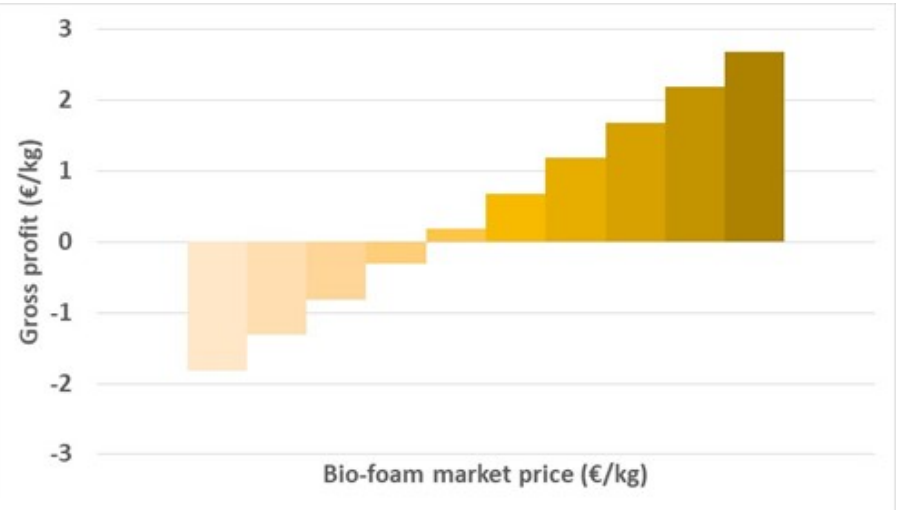

Fig. 3. Gross profit for bio-based PU foam. 
Therefore, considering the results of the environmental and economic analysis, it will be important in the future to try to reduce the consumption of DMI or find alternative catalysts to achieve full environmental and economic sustainability of the production process of polyurethane foams by using polyol from shrub biomass.

\section{CONCLUSIONS}

The present study models a cradle-to-gate LCA for the bio-based PU foam production from microwave liquefaction of riparian shrubs at industrial scale. Mass and energy flows about the polyol production were obtained at laboratory scale and the optimal liquefaction yield of $93.7 \%$ was achieved.

The overall results of LCA show that the liquefaction and foam synthesis steps were the major contributors to the environmental burden of the bio-foam, mostly due to the energy consumption and the use of DMI.

The comparison with the fossil PU foam highlighted that bio-foam presented a better performance in the global warming category with a reduction of the burden of $35 \%$ while the impact was significantly higher in the ozone depletion category. Therefore, it is difficult to claim the overall environmental superiority of the bio-based PU foam over the other. In the future, it will be fundamental to evaluate if the MDI/polyol ratio in the biobased formulation could be adopted, obtaining at the same time adequate physical performance. This result could also guarantee that the production of bio-foam could have a positive economic profit.

This work was supported by the Italian Ministry for Ecological Transition through the project "GEST-RIVER Gestione ecosostenibile dei territori a rischio inondazione e valorizzazione economica delle risorse".

\section{References}

1. H. M. C. C. Somarathna, S. N. Raman, D. Mohotti, A. A. Mutalib, K. H. Badri, Constr Build Mater, 190, 995-1014 (2018)

2. P. Furtwengler, L. Avérous, Polym Chem, 9(32), 4258-4287 (2018)

3. A. Fridrihsone, F. Romagnoli, V. Kirsanovs, U. Cabulis, J Clean Prod, 266, 121403 (2020)

4. B. L. Xue, J. L. Wen, R.C. Sun, Materials, 8(2), 586-599 (2015)

5. Y. Yan, H. Pang, X. Yang, R. Zhang, B. Liao, J Appl Polym Sci, 110(2), 1099-1111 (2008)

6. F. Chen, Z. Lu, J Appl Polym Sci, 111(1), 508-516 (2009)

7. R. A. Sheldon, ACS Sustainable Chem Eng, 6(1), 32-48 (2018)

8. A. Manzardo, A. Marson, M. Roso, C. Boaretti, M. Modesti, A. Scipioni, A. Lorenzetti, ACS omega, 4(9), 14114-14123 (2019)

9. A. Marson, M. Masiero, M. Modesti, A. Scipioni, A. Manzardo, ACS omega, 6(2), 1718-1724 (2021)

10. ISO 14040 International Standard. Environmental Management-Life Cycle Assessment-Principles and Framework. International Organisation for Standardization (2006) 
11. ISO 14044 International Standard. Environmental Management-Life Cycle Assessment- Requirements and Guidelines. International Organisation for Standardization (2006)

12. F. Piccinno, R. Hischier, S. Seeger, C. Som, J Clean Prod, 135, 1085-1097 (2016)

13. F. Piccinno, R. Hischier, S. Seeger, C. Som, J Clean Prod, 174, 283-295 (2018)

14. D. Koch, M. Paul, S. Beisl, A. Friedl, B. Mihalyi, J Clean Prod, 245, 118760 (2020)

15. L. J. Naimi, S. Sokhansanj, Fuel Process Technol, 173, 81-88 (2018)

16. F. Cotana, C. Buratti, M. Barbanera, E. Lascaro, Bioresour Technol, 198, 470-477 (2015)

17. M. Barbanera, C. Pelosi, A. R. Taddei, F. Cotana, Energy Conv Manag, 171, 1263$1272(2018)$

18. J. Y. Jung, J. H. Yu, E. Y. Lee, J Polym Environ, 26(8), 3493-3501 (2018)

19. J. M. Bermúdez, D. Beneroso, N. Rey-Raap, A. Arenillas, J. A. Menéndez, Chem Eng Process, 95, 1-8 (2015)

20. M. Barbanera, M. Castellini, G. Tasselli, B. Turchetti, F. Cotana, P. Buzzini, Fuel, 283, 118967 (2021)

21. A. G. Parvatker, M. J. Eckelman, ACS Sustain Chem Eng, 7(1), 350-367 (2018)

22. L. Chen, R. E. Pelton, T. M. Smith, J Clean Prod, 137, 667-676 (2016)

23. A. Manzardo, A. Marson, M. Roso, C. Boaretti, M. Modesti, A. Scipioni, A. Lorenzetti, ACS omega, 4(9), 14114-14123 (2019)

24. A. Fridrihsone, F. Romagnoli, V. Kirsanovs, U. Cabulis, J Clean Prod, 266, 121403 (2020)

25. M. Patel, C. Bastioli, L. Marini, E. Würdinger, Biopolym Online: Biol Chem Biotechnol Applic, 10 (2005)

26. R. P. B. Ashok, P. Oinas, K. Lintinen, G. Sarwar, M. A. Kostiainen, M. Österberg, Green Chem, 20(21), 4911-4919 (2018) 